\title{
Peertechz
}

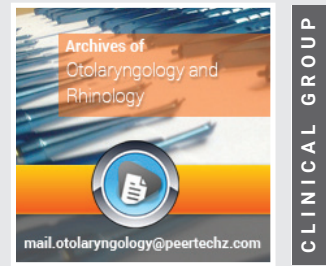

\section{Sofia Anastasiadou*}

MSc Student, ENT Senior House Officer, Charing Cross Hospital, London, UK

Received: 23 September, 2019

Accepted: 05 November, 2019

Published: 06 November, 2019

*Corresponding author: Dr Sofia Anastasiadou, MSc Student, ENT Senior House Officer, Charing Cross Hospital, London, UK,

E-mail: sofia.anastasiadou@nhs.net

ORCiD: https://orcid.org/0000-0002-4355-2070

https://www.peertechz.com

Check for updates
Review Article

CCrISP course-Care of critically Ill surgical patient: A critical educational evaluation of the curriculum

\section{Abstract}

Introduction: Education is a progressing and changing sector of all sciences. Especially in Medicine and Surgery, education has been evolving rapidly the past century and the changes are evident in strategies, methods, evaluation and assessment. Simulation, 3D encounters and small group sessions are replacing books, long exams and large group teaching lectures in an attempt to keep up with technology and innovation.

Methods: CCrISP is a Royal College of Surgeons course about the management of the critically ill surgical patient. Having that as an example, various educational theories and methods are analysed and presented in the following article.

Conclusion: Surgical education has a long more way to evolve in order to be effective, quick, safe and widely approved. Research is ongoing in various fields of surgical education and various methods are implemented in an attempt to deliver the best teaching to the future surgical trainees.

\section{Introduction}

Surgical education has been evolving rapidly recently. Changing from teacher-based lectures to more innovative teaching methodologies, surgical education has progressed a lot. In general, education science has been introducing various ways of transmitting knowledge as well as different assessment methods which are all under discussion and revision. Surgery is however a sector that requires a lot more that transmitting the theoretical knowledge as practical skills teaching is extremely important [1]. Until recently, surgical education was using very specific educational methods such as the halstedian technique which has been questioned as a model and is not in broad use anymore [2]. In addition, many have argued that the traditional technique of "see one, do one, teach one" should not be used anymore because of the increasing complexity of surgical procedures [3,4]. Consequently, it is evident that surgical education requires discussion revision and redesign to reflect progression in science of education as well as new surgical needs [5].

Simulation is one of the new trending techniques and numerous courses focus on that [6]. This report critically evaluates the "Care of the critically ill surgical patient (CCrISP)" course, organised and provided by Royal College of surgeons in the UK.

\section{Course description and outline}

The "Care of the critically ill surgical patient (CCrISP)" course is an interactive two-day course providing theoretical knowledge as well as practical skills regarding the acutely ill surgical patient [7]. Apart from the two intensive days, it also provides pre-course compulsory e-learning material. CCrISP is recognised by Health Education England and its curriculum is coherent with the National Surgical Training Curriculum [8]. It is very clear that the course addresses to core trainees and registrars as well as surgical practitioners, but foundation trainees are not suitable.

The course has 4 very well specified and clear learning outcomes which exist in the Royal College of Surgeon website. The potential participant is therefore very well prepared regarding what to expect from the course (Table 1). Indeed, the learning outcomes are designed exactly on the course information and vice versa, the course design and content

Table 1: CCrISP course learning outcomes by RCS.

Adopt a structured, comprehensive approach to managing surgical patients

Judge which patients are at most risk and plan to reduce their risk of adverse outcomes

Recognise the deteriorating patient

Model your non-operative technical skills in a safe environment 
reflect the learning outcomes effectively. As a result, they are all met by the end of the course and participants are able to perform each one of them with confidence. It is also very important that the learning outcomes as well as the curriculum of the course was sent out in advance. Communication of learning outcomes and course objectives is very important while designing a curriculum as per Harden's ten questions [9]. In CCrISP, I felt that the communication between the course administrators and the participants was very effective, preparing us to what to expect from the course.

CCrISP consists of various teaching and learning techniques such as lectures, demonstrations, simulated patient scenarios and case-based skill stations. The day starts at 8:00 and finishes at 17:30 with 2 coffee breaks and a lunch break in between, which last 90minutes in total. The participants are taught initially the basic principles of the acutely ill surgical patient, discuss it in small groups and watch a faculty demonstration. The following session is organised in 4 stations and participants rotate in groups of 6 (total of participants 24) mocking various clinical scenarios. There are also sessions organised only to practice skills that are again held in 4 stations. Each station has one tutor/supervisor so there is a $1: 4$ tutor/student ratio which is satisfactory enough as the level of the skills taught is not excessively demanding.

\section{Course curriculum}

CCrISP curriculum is structured in an effective way starting from basic medical knowledge that a core trainee is supposed to have, progressing in more complex theoretical and practical procedures. Its structure follows the PRISMS framework as well as the SPICES model [10] ensuring these principles are maintained throughout (Tables 2,3). The lectures were always less than one hour, structured in an interactive format in between the practical sessions, following Bligh's model [11]. A lot of questions related to the subject with various means of presentation such as powerpoint, videos, writing on smartboards and excellent presentational skills of the speakers kept the interest of the participants high. There are views supporting that elimination of lectures in the afternoon will be more useful, however there

Table 2: SPICES model [10].

Student-Centred

Problem-Based

Integrated

Community Based

Electives

Systematic

Table 3: PRISMS model [26]

Practice-based

Relevant to students and communities

Inter professional and interdisciplinary

Shorter courses in small units

Multisite locations

Symbiotic is ongoing discussion about what is the best time for a lecture, morning or afternoon [12]. The lectures were covering very well the theoretical part of the course focusing on understanding the basic clinical features of the critically ill patient. I personally believe that the lectures were very well organised, adequate but not excessive time was given and messages were interestingly and effectively transmitted to us.

Regarding the small group sessions, these were valuable to elaborate on what was taught during the lectures giving the opportunity to the participants to express themselves and to exchange views with peers [13]. However, guidance on what to discuss was minimal and participants ended up discussing irrelevant topics. My personal view is that a supervisor/ coordinator of the discussion would be useful to ensure effective exchange of views and productive conversation. Simulation and practical stations were also held in small groups, but each group had their own tutor to guide them. Indeed, that was very useful as the 1:4 tutor: student ratio allows good level of supervision and more interaction between all the members of the team. In addition, the faculty demonstration was again of great value so that the participants see the action plan and the management of the acutely ill patient in practice. Everything was shown in real time and participants were observing an excellent simulation understanding the principles of CCrISP in depth. Interestingly, following the demonstration, the participants had to implement themselves what they had seen as well as the knowledge they gained until that point of the day.

The second day followed the same structure, covering different cases of the acutely ill patient and different pathologies. The lectures focused on other reasons that could lead in an unwell patient, closing the literature requirements of the course. The scenarios changed and they combined more complex patients having pathologies from all the taught material. Participants were now asked to work in small groups addressing these patients to demonstrate they are able to implement the knowledge they acquired. The gradually advancing difficulty in scenarios was a very effective tool to engage participants of all levels to manage the acutely ill patients and build their confidence during the two days. I personally felt that escalation of scenario difficulty was designed in a relatively uneventful way, so that participants were not stressed or felt insecure. Dealing with a more complex patient seemed normal consequence of what we were learning. Overall, practical and theoretical sessions were very well paired so that we are able to deal with each one of the scenarios effectively.

\section{Assessment methods and feedback}

Before attending the course as well as after, participants need to answer online a pre-course questionnaire. It primarily consists of case-based scenarios that cover most of the pathologies of a critically ill patient. The pre-course material is very well structured, coherent and easily used. Submission is done via the RCS website and the process is self-explanatory. High participant motivation via web-based pre-course reading has been proven effective in the learning process [14] Consequently, a well-prepared interesting pre-course material 
was essential as it prepared the participants positively regarding the subsequent course. However, there was also post-course evaluation, which was compulsory to acquire the attendance certificate. In this way, learning outcome achievement could be assessed by the course administration comparing the participants results pre and post course attendance. This is consistent with the current view that evaluation of the outcomes of the course is considered an indicator of highquality teaching [13].

According to Nicol and McFarlane, feedback needs to have several features to be effective such as clarifying what good performance is and facilitating the development of selfassessment while closing up the gap between the teacher and the learner [15]. Black and William have also proven that written comments are more effective than marks [16] as students are more orientated on what needs to be improved. The tutors' feedback should avoid including an element of judging and needs to be transmitted and perceived as an opportunity to improve the participant's performance [17]. In addition, feedback should be conceptualised as a comment on the participant's general performance and focus on specific points of a task such as scenario or patient management. Indeed, feedback on somebody's "self" is not considered useful and does not actually lead to improvement of the task performance [13].

All the above were taken into consideration in CCrISP course feedback structure. To begin with, feedback and assessment are closely related educational activities and they frequently overlap [18]. In CCrISP course, written feedback was given to the participants without any personal judging apart from specific comments on the task performance. It was given as concurrent feedback by the end of each task by the tutor of each group. Given that when feedback is provided in a timely manner, it has increased value for students [13], I found that the immediate feedback was very useful. However, a summative feedback was given at the end of the day with overall comments for the participants' performance. It is proven that immediate feedback is more constructive while learning a specific task [19], however, delayed feedback is better associated with strategies in learning and it is also important [20]. The given feedback following Strandbygaard's views, was covering the main points for an effective feedback in a surgical environment. The feedback providers were the tutors and they were as many as the stations, which enabled them to give constructive and personalised feedback [21]. I personally felt, that each of my feedback comments were very well structured and were addressing real problems I was facing or had not spotted by that time. I also noticed that the second day I was already improving my skills trying to implement some of the first day's comments on my performance. Finally, it was impressive that even to tasks that my performance was below the satisfactory level, the feedback was very effective. Indeed, it was not poorly presented and was carefully communicated to me taking into consideration the crucial issue of failing the failed student [22].

However, feedback is an exchanging procedure coming from both sides, tutor and student [13]. Forms of feedback were given to us at the end of each day, covering the main learning outcomes and asking us how we felt regarding their achievement. I felt that same day feedback was very effective as we did not have the chance to forget any details and we were still very passionate to provide the course administrators with our ideas rather than we would have been if we were completing a feedback form from home several days later.

\section{Important positive features of CCrISP}

The CCrISP course presented several advantages compared to other surgical courses that I have attended in the past. Learning outcomes were well structured and were able to create a link between the curriculum and the assessment part of the course [23]. In terms of human factor, target group of participants was very well described before the registration to the course, so all the participants had the appropriate level to attend the course. This resulted in audience questions of adequate and interesting level as well as in a coherent and well communicating cohort of participants sharing similar needs. In addition, tutors were very carefully selected, as they were all experienced surgeons, making the scenarios much more lively and real. This helped me engage more with simulation and I was able to perform patient management as if I was under real circumstances.

Regarding the curriculum, as described above, difficulty in lectures and scenarios was increased on the second day, and escalation of the case complexity was gradual following the theoretical knowledge that we were acquiring. This model was clearly consistent with the Zimmerman's spiral curriculum and was very well implemented throughout the course. Different teaching methods, video and simulation were all used in order to keep the participants' interest as high as possible. From my point of view, holding the lectures in large groups and practical sessions/scenarios in small groups of 4 , was effective to achieve each one of the learning outcomes.

In addition, tutors in lectures were mostly facilitators of the learning process rather than dry transmitters of it which follows current state-of-art in education [13]. The course was also combining educative lectures with practical scenarios where knowledge acquired was implemented, which follows the educative method knowing how - showing how, helping participants to understand in depth the management of the surgical ill patient [24]. Finally, this course is more focused on the "learning surgeon" a term used frequently nowadays to describe the continuity of surgical education [1].

\section{Features of CCrISP for improvement}

Regarding features that require change and improvement, thankfully CCrISP course has minor disadvantages. The most important one, I believe is the intensity of the course in relation with self-evaluation. The hours are limited and the material that needs to be taught is excessive. However, the main points are still transmitted to the participant but there is no free time for practice unsupervised. According to Zimmerman, selfregulated learning is essential to learn effectively. Feedback and supervision act on top of that to add on the learning 
experience [25]. Consequently, learning objectives might be more easily achieved if some time is allocated for practice and reflection on performance.

\section{Summary}

In conclusion, CCrISP is a course offered by Royal College of Surgeons for intermediate and senior level surgical trainees. It combines various ways of teaching and assessment, allowing the candidate to learn in depth how to manage the acutely ill surgical patient. Overall, it is a well-structured course following the main contemporary tendencies of surgical education and creates a high quality and friendly but professional learning environment where the various learning objectives are effectively achieved.

\section{Acknowledgment}

I would like to thank my Imperial College tutors for inspiring me to write this critical review.

\section{References}

1. De Cossart L, Fish D (2005) Cultivating a thinking surgeon: New perspectives on clinical teaching, learning and assessment. Ann Surg 244: 158. Link: http://bit.ly/2PLhQs8

2. Barnes RW, Lang NP, Whiteside MF (1989) Halstedian technique revisited Innovations in teaching surgical skills. Ann Surg 210: 118-121. Link: http://bit.ly/2PMJBR3

3. Kotsis SV, Chung KC (2013) Application of the "see one, do one, teach one" concept in surgical training. Plast Reconstr Surg 131: 1194-1201. Link: http://bit.ly/2JPBjnK

4. Lenchus JD (2010) End of the "see one, do one, teach one" era: The next generation of invasive bedside procedural instruction. J Am Osteopath Assoc 110: 340-346. Link: http://bit.ly/36Cue3x

5. Frank JR, Mungroo R, Ahmad Y, Wang M, De Rossi S, et al. (2010) Toward a definition of competency-based education in medicine: a systematic review of published definitions. Med Teach 32: 631-637. Link: http://bit.ly/2WJ3jyq

6. Shaharan S, Neary P (2014) Evaluation of surgical training in the era of simulation. World J Gastrointest Endosc 6: 436-447. Link: http://bit.ly/2Njc7rG

7. Anon (2019) Care of the crtitically ill surgical patient (CCrISP) course. Link: http://bit.ly/2r6ymbN

8. Anon (2019) Surgical Training Curriculum. Link: http://bit.ly/34v2b4b

9. Harden RM (1986) Ten questions to ask when planning a course or curriculum. Association for the Study of Medical Education 20: 356-365. Link: http://bit.ly/33hn037
10. Harden RM, Sowden S, Dunn WR (1984) Educational strategies in curriculum development: the SPICES model. Med Educ 18: 284-297. Link: http://bit.ly/34zjsJQ

11. Donald B (1998) What's the Use of Lectures? Link: http://bit.ly/34wWaUU

12. Round J, Lom B (2015) In Situ Teaching: Fusing Labs \& Lectures in Undergraduate Science Courses to Enhance Immersion in Scientific Research. J Undergrad Neurosci Educ 13: A206-A214. Link: http://bit.ly/2NH0GZZ

13. Cantillon, Wood and Yardley (2017) ABC of Learning and Teaching in Medicine, 3rd Edition. Link: http://bit.ly/2WJ2Axc

14. Wu-Yuin $\mathrm{H}$ (2012) The effects of pre-reading and sharing mechanisms on learning with the use of annotations. TOJET: The Turkish Online Journal of Educational Technology 10: 234-249. Link: http://bit.ly/33hDLLf

15. David N, Debra MD (2006) Formative assessment and self-regulated learning: A model and seven principles of good feedback practice. Studies in Higher Education 31: 199-218. Link: http://bit.ly/32cT86p

16. Black P, Wiliam D (1998) Inside the Black Box: Raising Standards Through Classroom Assessment. Phi Delta Kappa. Link: http://bit.ly/2r9elMk

17. Timperley JH (2007) The Power of Feedback. Review of Educational Research 77: 81-112. Link: http://bit.ly/2NhTIBi

18. Cantillon, P. and J. Sargeant (2008) Giving feedback in clinical settings. BMJ 337: a1961. Link: http://bit.ly/36B7H7q

19. Kulik J, Kulik C (1988) Timing of Feedback and Verbal Learning. Review of Educational Research 58: 79-97. Link: http://bit.ly/2JPWwh8

20. Hattie and Timperlay (2007) The Power of Feedback. Review of Educational Research 77: 81-112. Link: http://bit.ly/2NhTIBi

21. Strandbygaard J, Scheele F, Sørensen JL (2017) Twelve tips for assessing surgical performance and use of technical assessment scales. Med Teach 39: 32-37. Link: http://bit.ly/2JS5Jpl

22. Dudek NL, Marks MB, Regehr G (2005) Failure to fail: the perspectives of clinical supervisors. Acad Med 80: S84-87. Link: http://bit.ly/2PJQCSJ

23. Ravit and Hmelo-Silver (2009) Learning progressions: Aligning curriculum, instruction and assessment. Journal of research in science teaching 46: 606609. Link: http://bit.ly/2JNWeaG

24. Baez A, Eckert-Norton M, Morrison A (2004) Knowing how and showing how: Interdisciplinary collaboration on substance abuse skill OSCEs for medical, nursing and social work students. Subst Abus 25: 33-37. Link: http://bit.ly/33dOjv0

25. Schunk DH, Zimmerman BJ (1998) Self-regulated learning: From teaching to self-reflective practice. New York; London, Guilford Press. Link: http://bit.ly/34BKeRP

26. Remesh A (2017) Curriculum design principles for developing a module in medical education. Progress In Medical Sciences 1: 34-37. Link: http://bit.ly/2PMoFtx

Copyright: @ 2019 Anastasiadou S. This is an open-access article distributed under the terms of the Creative Commons Attribution License, which permits unrestricted use, distribution, and reproduction in any medium, provided the original author and source are credited. 